\title{
RELATIVE ACTIVITIES OF ACID PHOSPHATASE AND DIPEPTIDYL PEPTIDASE II IN REGENERATING RAT SKELETAL MUSCLE FIBRES
}

\author{
Keith Niven GHRISTIE and Calum THOMSON \\ Department of Anatomy, The University of Dundee, \\ Scotland DD1 4HN, U.K.
}

Received for publication July 22, 1987 and in revised form September 16, 1987

\begin{abstract}
The histochemical activities of acid phosphatase and dipeptidyl peptidase II were determined quantitatively in regenerating rat soleus fibres up to five weeks after an ischaemic insult with 5-hydroxytryptamine. A measure of the total enzyme content per fibre was determined by multiplying mean fibre area by the mean absorbance of the enzyme final reaction product. Acid phosphatase content was $21 \%$ lower than control levels during the first two weeks and $18 \%$ higher in the remaining three weeks; the mean absorbance of the reaction product correlated significantly with fibre area $(r=0.922)$. Dipeptidyl peptidase II activity was $14 \%$ lower during the first three weeks, $2 \%$ higher in the fourth week and $14 \%$ higher in the fifth week. The correlation of mean absorbance of the reaction product of this enzyme with fibre area $(r=0.792)$ was not as good as for acid phosphatase but was significant.
\end{abstract}

Increased activity of acid proteases and hydrolases is often associated with degeneration and wasting in skeletal muscle, and is a characteristic feature of myopathies in man and animals $(4-6,9,20,25)$. However, there is also evidence of elevated activities in developing and regenerating muscle, particularly of the cathepsins $(8,19)$, acid phosphatase and the glucosidases $(15-17,23,24)$.

As part of continuing investigations into the role of this class of enzymes in skeletal muscle, it was decided to examine the activities of acid phosphatase (EC 3.1.3.2) and dipeptidyl peptidase II (DPPII) (EC 3.4.14.2) in regenerating rat soleus fibres to see if there is any correlation between fibre size and enzyme activity. Regenerating fibres were obtained by injecting rats with a single dose of 5-hydroxytryptamine, which induces ischaemia and damage to the muscles followed by complete recovery $(3,7,12,14)$. The enzyme activities of the fibres were revealed with histochemical techniques at one week intervals up to five weeks after the insult. The mean absorbances of the final reaction products deposited in the fibres were measured with a scanning microdensitometer and correlated with mean fibre area.

\section{MATERIALS AND METHODS}

\section{Animals and enzyme procedures}

Twenty outbred, male, 3-month-old Wistar rats weighing about $250 \mathrm{~g}$ were each injected intraperitoneally with the equivalent of $10 \mathrm{mg} 5$-hydroxytryptamine free base 
per kg body weight. The creatine sulphate complex was obtained from Sigma London, Ltd. and dissolved in physiological saline. A further 4 rats were injected with saline alone to serve as controls. All rats were allowed free access to water and food. Four rats were killed each week by stunning and cervical dislocation and the soleus muscles from both legs removed. Mid-belly portions supported in 10\% gum tragacanth on cork discs were quenched in isopentane cooled with liquid nitrogen. All samples were stored in a liquid nitrogen refrigerator until the last animals had been killed at 5 weeks. $10 \mu \mathrm{m}$-thick sections were cut in a motorised cryostat run at constant speed, and either collected on clean coverslips or, in the case of DPPII, mounted on washed, dry semipermeable membranes over a gelled medium. Fresh sections on coverslips were incubated for acid phosphatase at $37^{\circ} \mathrm{C}$ for $1.5 \mathrm{hr}$ in a buffered medium containing naphthol AS-BI phosphate and freshly hexazotised pararosaniline in the presence of $20 \mathrm{mM} \mathrm{MnCl}_{2}$ (10). $5 \mathrm{mM} \mathrm{NaF}$ was used to confirm the identity of acid phosphatase. DPPII was assayed with L-lysyl-L-proline-4-methoxy- $\beta$ naphthylamide as described by Christie and Stoward (3) using a semipermeable membrane technique. Appropriate controls were employed (3). All samples were assayed on the same day with the same batch of substrate medium.

Densitometry and area measurements

A Vickers M85 scanning microdensitometer was employed using a X40 objective and a No. 2 scanning spot at $530 \mathrm{~nm}$, the absorption maxima of the reaction products. The grouped mean absorbance of 24 regenerating fibres in each soleus was determined for each week after 5-HT administration. In earlier experiments, it was found that this number of fibres was more than sufficient to give a constant cumulative mean absorbance and standard deviation. The areas (in $\mu \mathrm{m}^{2}$ ) of 24 regenerating fibres in each soleus were measured on a MOP Digiplan (Kontron Ltd.) from enlarged photomicrographs of Haematoxylin and Eosin stained sections. The amount of enzyme reaction product in the fibres was obtained by multiplying mean area by mean absorbance at $530 \mathrm{~nm}$. The correlation of mean absorbance on mean fibre area was determined for each enzyme.

\section{RESULTS}

\section{Histology and qualitative cytochemistry}

One week after 5-HT administration, immature fibres with prominent vacuolar central nuclei and a reticular basophilic network were evident (Fig. 1). Three weeks after 5-HT administration, reticular basophilia was absent and central nuclei were seen in only about $10 \%$ of the fibres (Fig. 2). At five weeks central nuclei were rarely

FIG. 1. Rat soleus one week after administration of 5-HT. Regenerating fibres with central nuclei and basophilic reticular network are prominent at this stage. Haematoxylin and Eosin. $\times 950$ (total magnification)

Fig. 2. Rat soleus three weeks after 5-HT administration. Only a few fibres have central nuclei and the basophilic network is absent. Haematoxylin and Eosin. $\quad \times 950$

FIG. 3. Rat soleus one week after 5-HT administration. A strong acid phosphatase reaction product is present in the small regenerating fibres. Note the ring-like product which normally surrounds central nuclei. $\times 950$

FIG. 4. Rat soleus one week after 5-HT administration. Dipeptidyl peptidase II activity is demonstrated as an evenly distributed particulate product in the young fibres. $\quad \times 950$ 

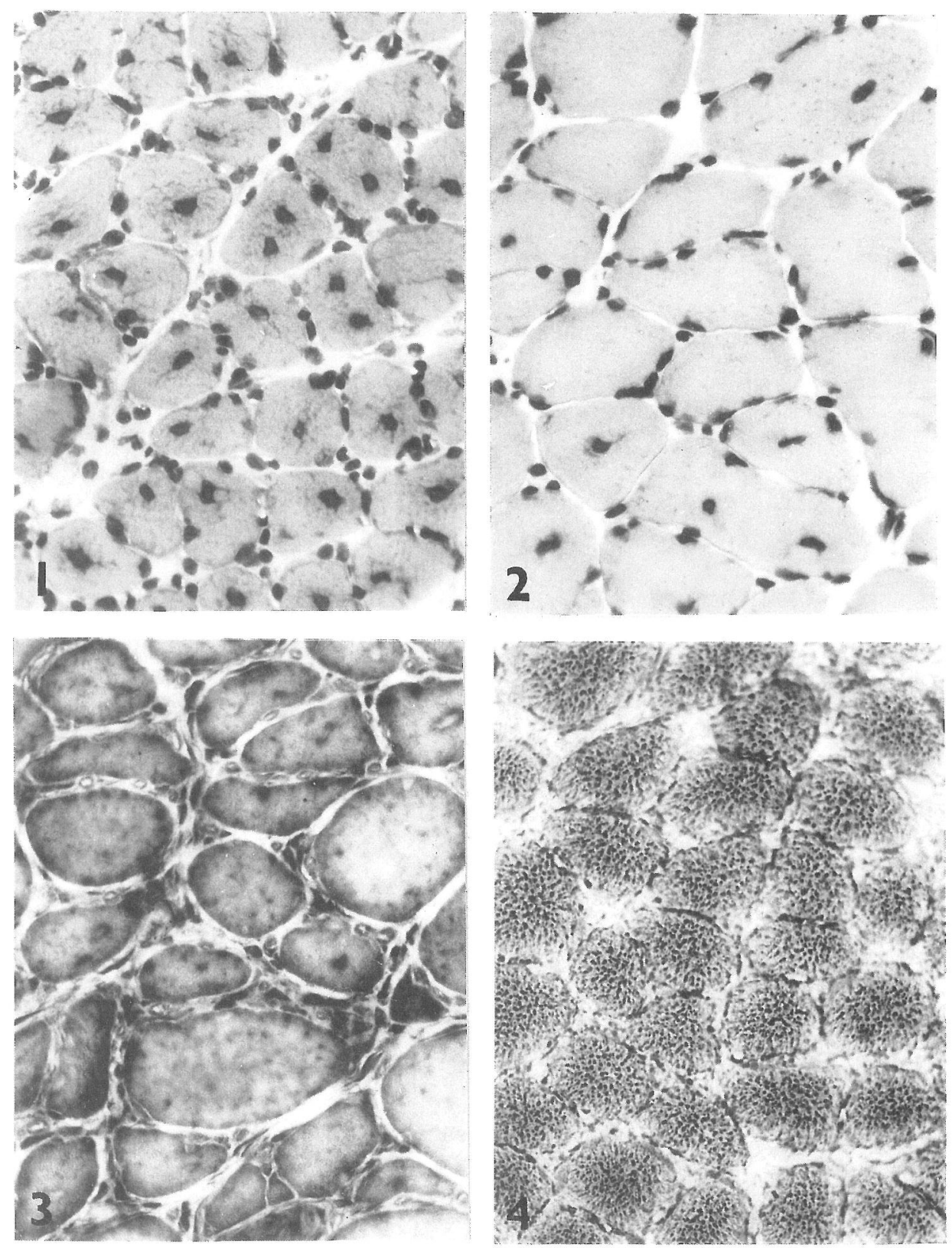
seen.

Acid phosphatase exhibited a substantial particulate and diffusely distributed enzyme reaction product throughout the sarcoplasm of regenerating fibres one week after 5-HT insult. The strongest particulate product occurred around central nuclei (Fig. 3).

Dipeptidyl peptidase II displayed a strong, evenly-distributed particulate product in the regenerating fibres one week after 5-HT administration (Fig. 4). Reaction product was also prominent in adjacent mononuclear cells, connective tissue elements and capillaries.

\section{Fibre growth}

One week after 5-HT insult, mean fibre cross-sectional area was $913.40 \pm 136.95$ $\mu \mathrm{m}^{2}$, or $22 \%$ of the mean area of normal mature fibres $\left(4172.76 \pm 1001.02 \mu \mathrm{m}^{2}\right)$. At three weeks post-5-HT the fibres had attained $56 \%$, and by five weeks $89 \%$ (3701.68 $\left.\pm 1098.01 \mu \mathrm{m}^{2}\right)$ of normal fibres (Fig. 5).

Quantitative enzyme cytochemistry

(1) Acid phosphatase. The absorbance of the reaction product was highest in the one-week-old fibres and decreased progressively to near normal levels by week five (Fig. 6). The total amount of enzyme reaction product per fibre was, by comparison with normal fibres, about $21 \%$ lower during the first two weeks of recovery. A mean increase of $18 \%$ over normal levels occurred between the third and fifth weeks (Fig. 7). There was a good correlation between acid phosphatase mean absorbance and fibre area $(\mathrm{r}=0.922)$ (Fig. 8).

(2) Dipeptidyl peptidase II. The absorbance of DPPII reaction product was highest during the first week post-5-HT (4-fold above normal basal levels). It decreased

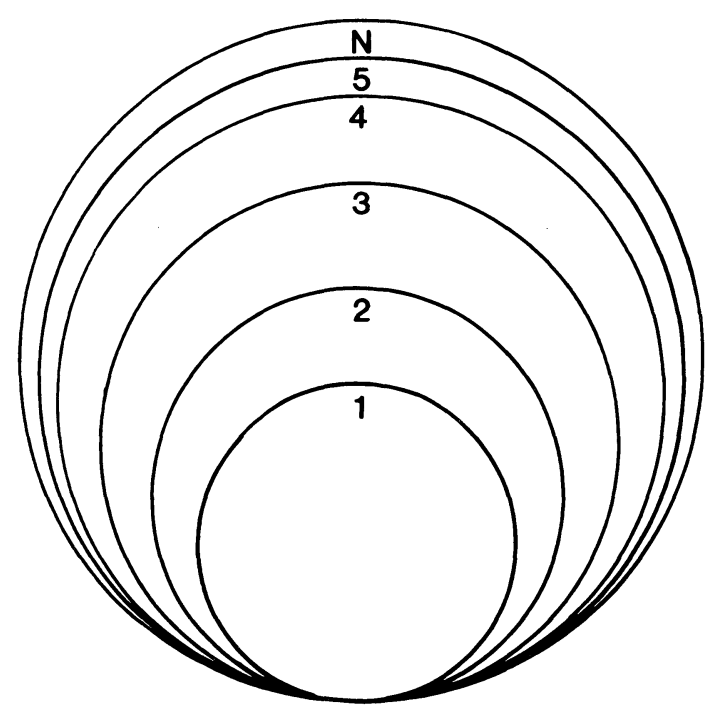

FIG. 5. Proportional representation of the increase in fibre size from one to five weeks after 5-HT administration $\left(913.40 \pm 136.95-3701.68 \pm 1098.01 \mu \mathrm{m}^{2}\right) . \quad \mathrm{N}=$ area of normal mature soleus fibres $\left(4172.76 \pm 1001.02 \mu \mathrm{m}^{2}\right)$. (All means \pm S.D.) 


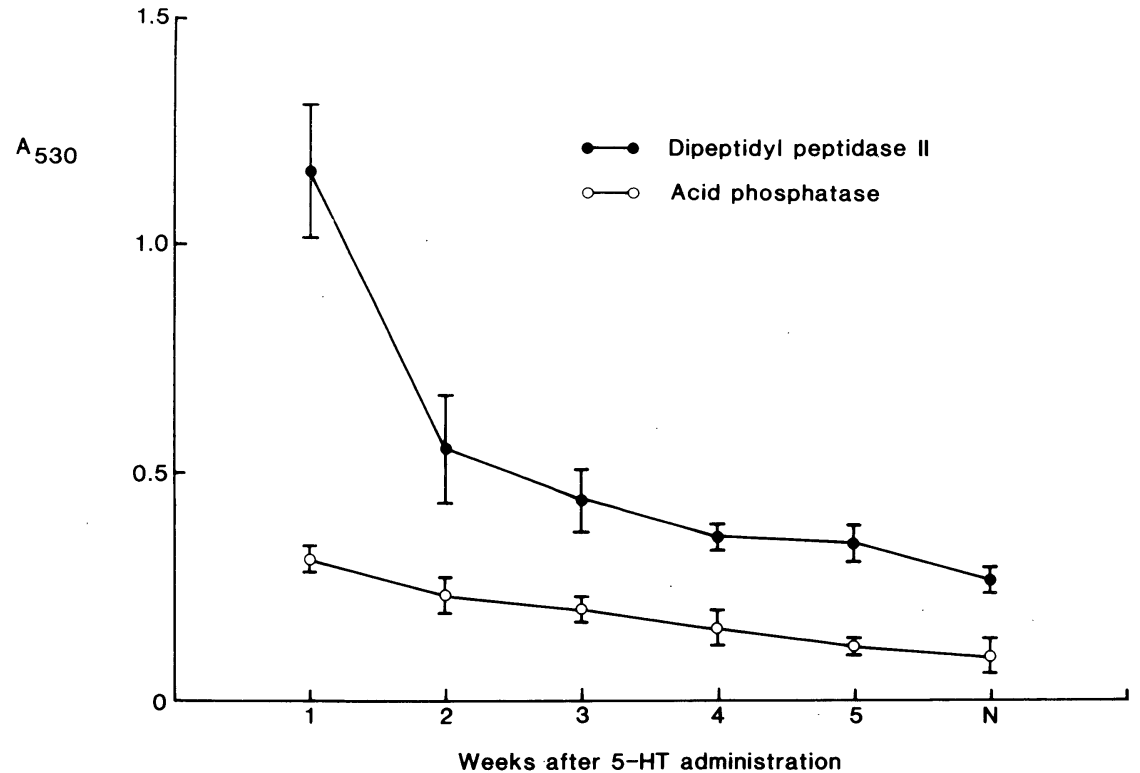

FIG. 6. Absorbance of acid phosphatase and DPPII enzyme final reaction products in regenerating fibres versus time after 5-HT administration ( $\mathrm{N}=$ normal fibes).

Acid phosphatase

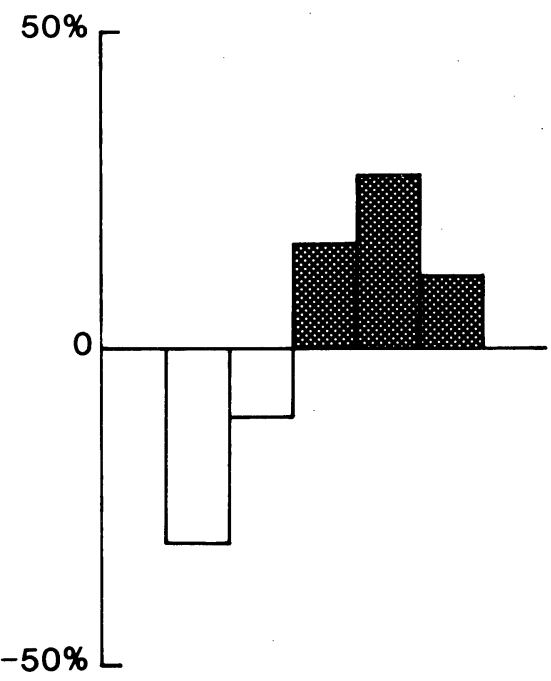

Dipeptidyl peptidase II

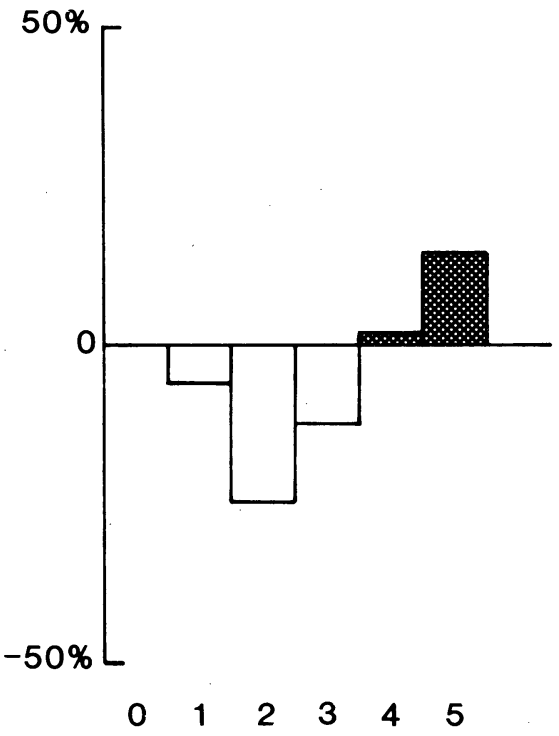

Fig. 7. Histograms illustrating the changes in the amount of enzyme final reaction product in regenerating fibres as a function of time after $5-\mathrm{HT}$ administration. 


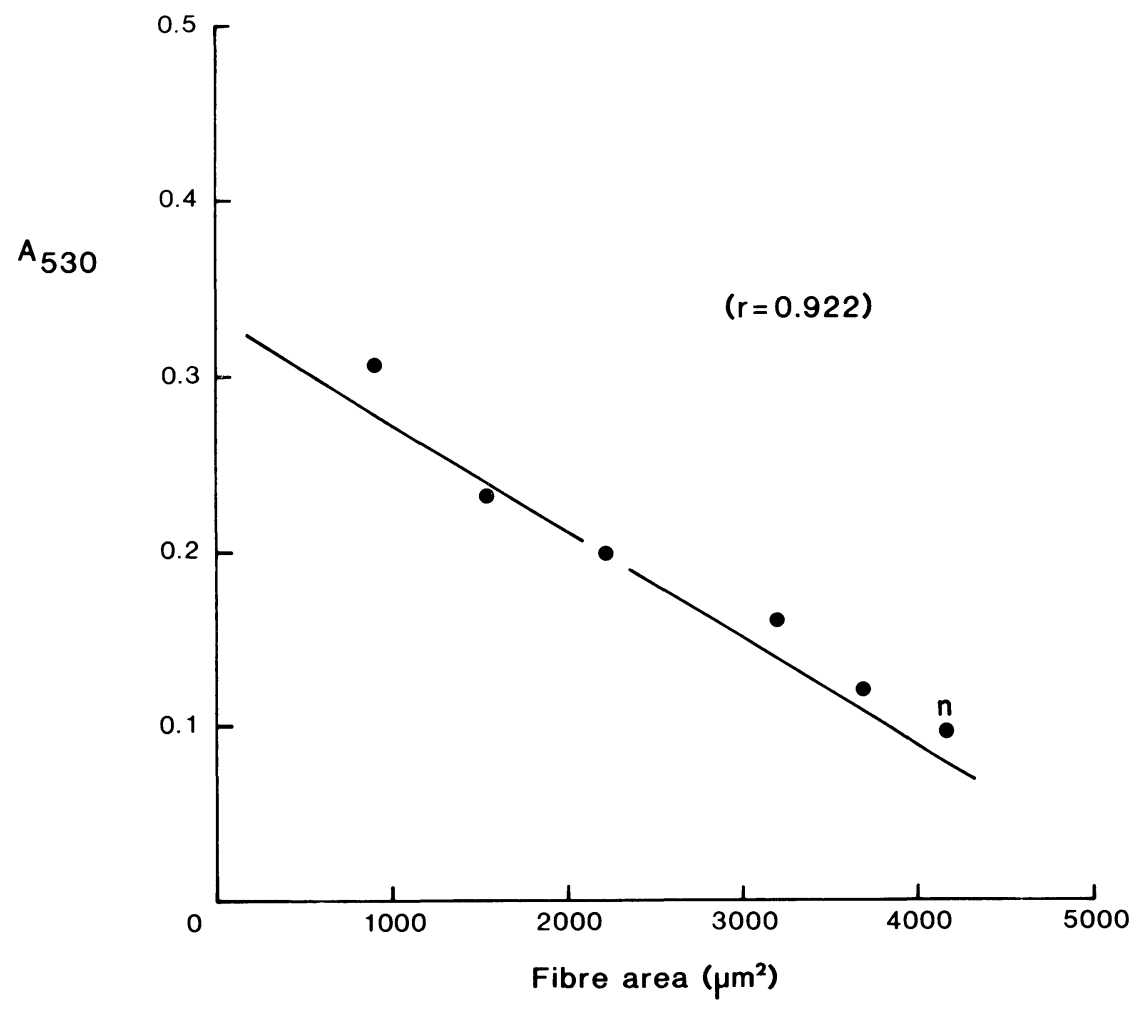

FIG. 8. Correlation of acid phosphatase mean absorbance with fibre area $(r=0.922), n=$ normal fibres.

steadily over the following four weeks to approximately normal (Fig. 6). The amount of reaction product was on average $14 \%$ lower than normal fibres during the first three weeks, $2 \%$ higher in the fourth week and 14\% higher in week five (Fig. 7). The correlation between the mean absorbance of DPPII reaction product and fibre area $(\mathrm{r}=0.792)$ was not as good as that for acid phosphatase (Fig. 9), but was significant $(\mathrm{p}=<0.05)$.

\section{DISCUSSION}

Muscle recovering from a 5-HT insult seems to be a good model for studying the enzymology of fibre regeneration. Up to one week after 5-HT administration there are numerous degenerating foci as well as regenerating myocytes. From one week onwards regeneration predominates with many discrete areas of developing fibres evident. This permits microdensitometric measurements of enzyme reaction product to be performed on individual regenerating fibres without interference from adjacent degenerating fibres and inflammatory cells whose hydrolytic enzymes might enter them. Biochemical assays of the enzymes during the first ten days or so after insult 


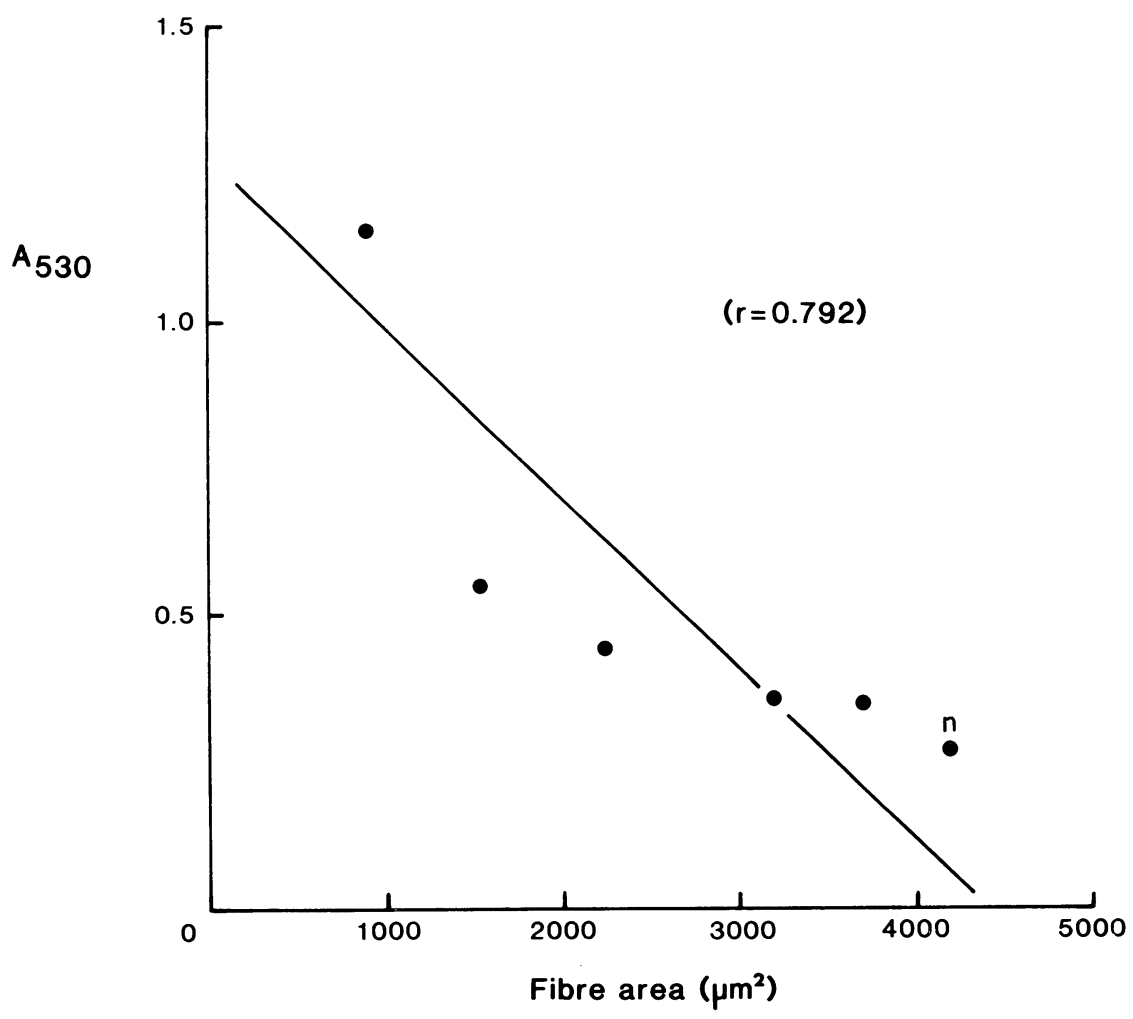

FIG. 9. Correlation of dipeptidyl peptidase II mean absorbance with fibre area; $(r=0.792), n=$ normal fibres.

would have been meaningless since both enzymes are present in abundance in connective tissue elements and the inflammatory exudate $(2,11)$.

Qualitative observations and quantitative cytochemical assays of acid phosphatase and DPPII in regenerating fibres up to about three weeks after insult give the impression that the activities of both enzymes are much higher than in normal, non-insulted fibres (Figs. 3, 4,6). However, when the total amount of enzyme reaction product per fibre is calculated, acid phosphatase and DPPII only begin to exceed normal levels of activity at three and four weeks respectively after $5 \mathrm{HT}$ insult (Fig. 7). The close correlation, particularly for acid phosphatase, between fibre cross-sectional area and absorbance, suggests that the amount of enzyme protein does not change significantly during growth. Paradoxically, however, when the total amount of enzyme reaction product per fibre is expressed as a function of time, it does change from lower than normal levels during the first two to three weeks to higher levels during the latter stages of growth (Fig. 7).

It was expected that DPPII would exhibit higher than normal levels of activity during the early stages of regeneration. During the initial phase of regeneration, amino acids are possibly derived from the breakdown of necrotic fibres and en- 
domysial connective tissue by interstitial cells, for example macrophages, for endocytosis by the developing muscle cells. DPPII could contribute to this process since in vitro it is capable of hydrolysing a variety of collagen-related tripeptides (11).

Ultrastructural studies of acid phosphatase in skeletal muscle reveal that it is chiefly localised (in lysosomal-like structures) in the subsarcolemmal region and prominently adjacent to peripheral or central nuclei (1). Many subcellular structures in skeletal muscle exhibit acid phosphatase activity, for example, the T-tubular system $(18,22)$, sarcoplasmic reticulum $(1,21,22)$, Golgi apparatus (24) and so-called tubular lysosomes (13). The role of hydrolytic enzymes in skeletal muscle is poorly understood, but is presumably related to the degradation of dietary proteins and recycling of existing proteins as part of growth and homeostasis.

It emerges from this study that assessment of enzyme activity in muscle fibres based purely on subjective criteria such as 'intensity of colour' or absorbance is limited. Where enzyme reaction product is uniformly distributed as in skeletal muscle fibres, the total amount of reaction product per cross-sectional profile provides a more useful indicator of the expression of activity.

\section{REFERENCES}

1. Christie, K. N. and Stoward, P. J.: A cytochemical study of acid phosphatase in dystrophic hamster muscle. J. Ultrastruct. Res. 58; 219-234, 1977.

2. Christie, K. N. and Modi, B. V.: Some histochemical observations on invasive cells in a myopathy induced in rats with 5-hydroxytryptamine. Neuropath. Appl. Neurobiol. 10; 447-460, 1984.

3. Christie, K. N. and Stoward, P. J.: Dipeptidyl peptidase II in the soleus muscle of rats treated with 5-hydroxytryptamine. Histochemistry 1987, (in press).

4. Cornelio, F. and Dones, I.: Muscle fibre degeneration and necrosis in muscular dystrophy and other muscle diseases: cytochemical and immunocytochemical data. Ann. Neurol. 16; 694-701, 1984.

5. Kar, N. C. and Pearson, G. M.: Muscular dystrophy and activation of proteinases. Muscle Nerve 1; 308-313, 1978.

6. Kar, N. C. and Pearson, C. M.: Activity of some proteolytic enzymes in normal and dystrophic human muscle. Clin. Biochem. 12; 37-39, 1979.

7. Kelts, K. A. and Kaiser, K. K.: Experimental ischaemic myopathy. J. Neurol. Sci. 40; 23-27, 1979 .

8. Kirschke, H., Wood, L., Roisen, F. J. and Bird, J. W. C.: Activity of lysosomal cysteine proteinase during differentiation of rat skeletal muscle. Biochem. J. 214; 871-877, 1983.

9. Li, J. B.: Protein synthesis and degradation in skeletal muscle of normal and dystrophic hamsters. Am. J. Physiol. 239; E401-406, 1980.

10. Lojda, Z., Gossrau, R. and Schiebler, T. H.: Enzyme Histochemistry, Springer-Verlag, Berlin, 1979, pp. 72-73.

11. McDonald, J. K. and Schwabe, G.: Dipeptidyl peptidase II of bovine dental pulp. Biochem. Biophys. Acta 616; 68-81, 1980.

12. Munsat, T. L., Hudgson, P. and Johnson, M. A.: Experimental serotonin myopathy. Neurol. (Minneap.) 27; 772-782, 1977.

13. Okada, T., Robinson, J. M. and Karnovsky, M.J.: Cytochemical localization of acid phosphatase in striated muscle. Histochemistry 85; 177-183, 1986.

14. O'Steen, W. K., Barnard, J. L. and Yates, R. D.: Morphologic changes in skeletal muscle induced by serotonin treatment: a light and electron microscopic study. Exptl. Mol. Path. 7; $145-155,1967$. 
15. Salminen, A. and Kihlström, M.: Lysosomal changes in mouse skeletal muscle during the repair of exercise injuries. Muscle Nerve 8; 269-279, 1985.

16. Shannon, A. D., Adams, E. P. and Courtice, F. C.: The lysosomal enzymes acid phosphatase and $\beta$-glucuronidase in muscle following a period of ischaemia. Aust. J. Exptl. Biol. Med. Sci. 52; 157-171, 1974.

17. Shannon, A. D. and Courtice, F. C.: The lysosomal enzyme N-acetyl- $\beta$-glucosaminidase in rabbit muscle following a period of ischaemia. Pathology 7; 25-33, 1975.

18. Spicer, S. S., Buse, M. G. and Setser, M. E.: Ultrastructural localization of acid phosphatase in denervated and diabetic striated muscles. Am. J. Pathol. 99; 603-619, 1980.

19. St. John, A. C., McElligott, M. A., Lee, J. A., Keaton, K. S., Yorke, G., Roisen, F. J. and Bird, J. W. C.: Lysosomal proteinases in cultured muscle cells. In Proteinases and their Inhibitors. Structure, Function and Applied Aspects, ed. by V. Turk and L.J. Vitale, Pergamon Press, Oxford, 1981, pp. 13-23.

20. Takala, T. E. S., Myllyla, V. V., Salminen, A., Tolonen, V. and Hassinen, I. E.: Lysosomal and non-lysosomal hydrolases of skeletal muscles in neuromuscular diseases. Arch. Neurol. 40; 541-544, 1983.

21. Trout, J. J., Stauber, W. T. and Schottelius, B. A.: Cytochemical observations of two distinct acid phosphatase-reactive structures in anterior latissimus dorsi muscle of the chicken. Histochem. J. 11; 223-230, 1979.

22. Trout, J. J., Stauber, W. T. and Schottelius, B. A.: Degeneration and regeneration in denervated tonic and phasic skeletal muscle: morphology and acid phosphatase cytochemistry. Virchows Arch. (Gell Pathol.) 38; 67-76, 1981.

23. Vihko, V., Rantamaki, J. and Salminen, A.: Exhaustive physical exercise and acid hydrolase activity in mouse skeletal muscle. Histochemie 57; 237-249, 1978.

24. Wakayama, Y., Matsuzaki, H. and Nakai, Y.: Golgi apparatus: distinct structure of acid phosphatase localization in regenerating human skeletal muscle fibres. Dev. Neurosci. 6; 152$160,1984$.

25. White, M. G., Stoward, P. J., Christie, K. N. and Anderson, J. M.: Proteases in normal and diseased human skeletal muscle: a preliminary histochemical survey. Histochem. J. 17; 819832, 1985. 